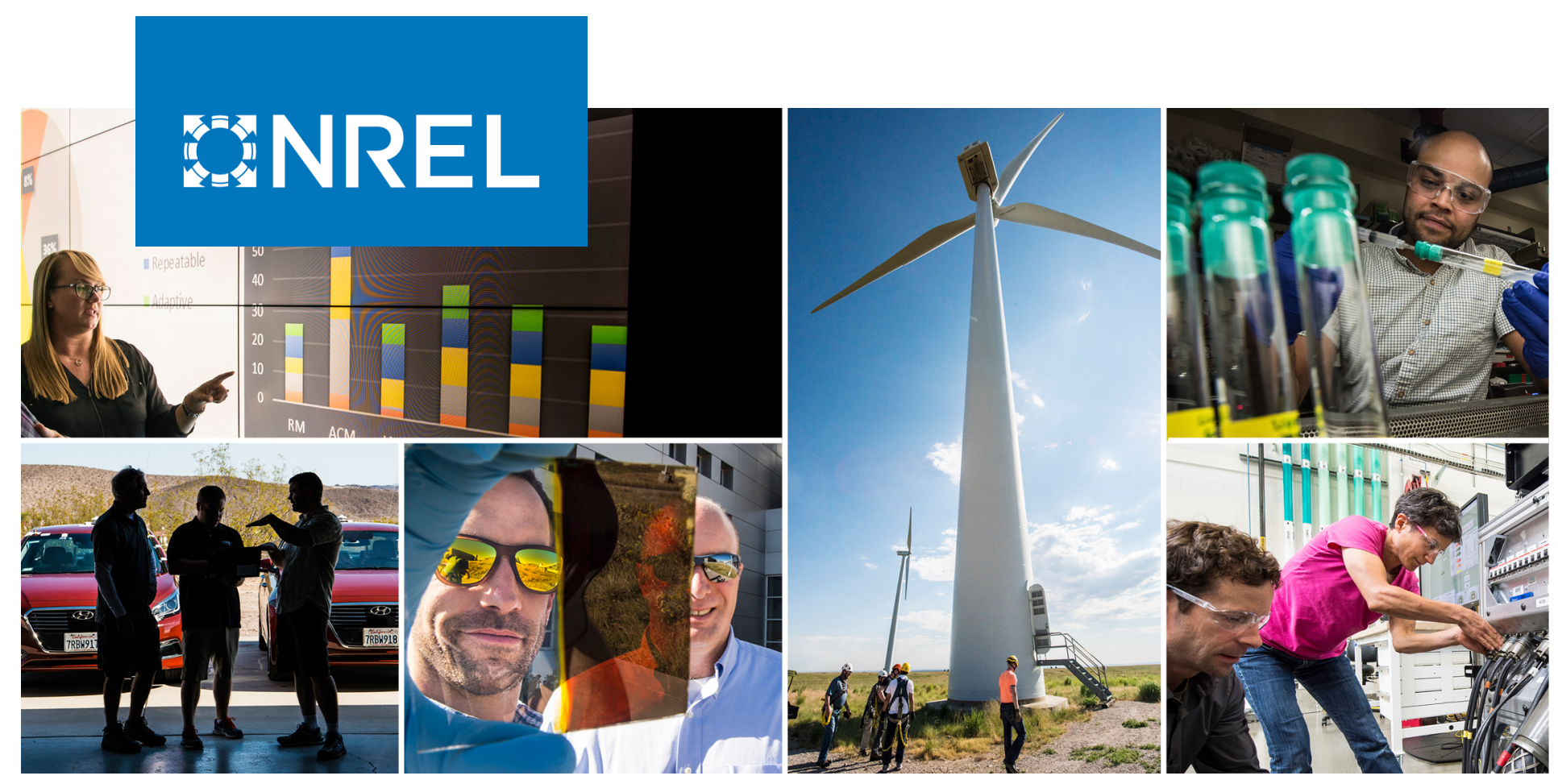

\title{
Determination of Cellulosic Glucan Content in Starch Containing Feedstocks
}

\section{Laboratory Analytical Procedure (LAP)}

Issue Date: February 26, 2021

Katie Michel, Justin Sluiter*, Courtney Payne, Ryan Ness, Brittany Thornton, Michelle Reed, Alexa Schwartz, and Ed Wolfrum

National Renewable Energy Laboratory

${ }^{*}$ Corresponding author

NREL is a national laboratory of the U.S. Department of Energy Office of Energy Efficiency \& Renewable Energy

Operated by the Alliance for Sustainable Energy, LLC

This report is available at no cost from the National Renewable Energy Laboratory (NREL) at www.nrel.gov/publications.
Technical Report

NREL/TP-2800-76724

February 2021 


\section{EAREL}

\section{Determination of Cellulosic Glucan Content in Starch Containing Feedstocks}

\section{Laboratory Analytical Procedure (LAP)}

Issue Date: February 26, 2021

Katie Michel, Justin Sluiter*, Courtney Payne, Ryan Ness, Brittany Thornton, Michelle Reed, Alexa Schwartz, and Ed Wolfrum

National Renewable Energy Laboratory

\section{Suggested Citation}

Michel, Katie, Justin Sluiter, Courtney Payne, Ryan Ness, Brittany Thornton, Michelle Reed, Alexa Schwartz, and Ed Wolfrum. 2021. Determination of Cellulosic Glucan Content in Starch Containing Feedstocks. Laboratory Analytical Procedure (LAP), Issue Date: February 26, 2021. Golden, CO: National Renewable Energy Laboratory. NREL/TP-2800-76724. https://www.nrel.gov/docs/fy21osti/76724.pdf.

${ }^{*}$ Corresponding author

NREL is a national laboratory of the U.S. Department of Energy Office of Energy Efficiency \& Renewable Energy Operated by the Alliance for Sustainable Energy, LLC

This report is available at no cost from the National Renewable Energy Laboratory (NREL) at www.nrel.gov/publications.

Contract No. DE-AC36-08GO28308
Technical Report

NREL/TP-2800-76724

February 2021

National Renewable Energy Laboratory 15013 Denver West Parkway Golden, CO 80401

303-275-3000 • www.nrel.gov 


\section{NOTICE}

This work was authored by the National Renewable Energy Laboratory, operated by Alliance for Sustainable Energy, LLC, for the U.S. Department of Energy (DOE) under Contract No. DE-AC3608GO28308. Funding provided by U.S. Department of Energy Office of Energy Efficiency and Renewable Energy Bioenergy Technologies Office. The views expressed herein do not necessarily represent the views of the DOE or the U.S. Government.

This report is available at no cost from the National

Renewable Energy Laboratory (NREL) at

www.nrel.gov/publications.

U.S. Department of Energy (DOE) reports produced

after 1991 and a growing number of pre-1991

documents are available

free via www.OSTI.gov.

Cover Photos by Dennis Schroeder: (clockwise, left to right) NREL 51934, NREL 45897, NREL 42160, NREL 45891, NREL 48097, NREL 46526.

NREL prints on paper that contains recycled content. 


\section{DISCLAIMER}

The Standard Biomass Analytical Methods (Methods) are provided by the National Renewable Energy Laboratory (NREL), which is operated by Alliance for Sustainable Energy, LLC (Alliance) for the U.S. Department of Energy (DOE). These methods were developed and written for commercial research and educational use only.

Access to and use of these Methods shall impose the following obligations on the user. The user is granted the right, without any fee or cost, to use, copy, modify, alter, enhance, and distribute these Methods for any purpose whatsoever, except commercial sales, provided that this entire notice appears in all copies of the Methods. The user agrees to credit NREL/Alliance in any publications that result from the use of these Methods. The user also understands that NREL/Alliance is not obligated to provide the user with any support, consulting, training, or any training or assistance of any kind with regard to the use of these Methods or to provide the user with any updates, revisions, or new versions.

THESE METHODS ARE PROVIDED BY NREL/Alliance "AS IS" AND ANY EXPRESS OR IMPLIED WARRANTIES, INCLUDING BUT NOT LIMITED TO, THE IMPLIED WARRANTIES OF MERCHANTABILITY AND FITNESS FOR A PARTICULAR PURPOSE ARE DISCLAIMED. IN NO EVENT SHALL NREL/Alliance/DOE BE LIABLE FOR ANY SPECIAL, INDIRECT, OR CONSEQUENTIAL DAMAGES OR ANY DAMAGES WHATSOEVER, INCLUDING BUT NOT LIMITED TO, CLAIMS ASSOCIATED WITH THE LOSS OF DATA OR PROFITS, WHICH MAY RESULT FROM AN ACTION IN CONTRACT, NEGLIGENCE, OR OTHER TORTIOUS CLAIM THAT ARISES OUT OF OR IN CONNECTION WITH THE ACCESS, USE, OR PERFORMANCE OF THESE METHODS. 


\section{Introduction}

1.1. Carbohydrates make up a major portion of biomass samples. These carbohydrates are polysaccharides constructed primarily of glucose, xylose, arabinose, galactose, and mannose monomeric subunits. One such polysaccharide is starch, which is present in certain types of biomass. Starch will contribute to the overall glucose measurement when it breaks into the glucose subunit. Starch is often a more readily accessible source of glucose than structurally bound glucose polymers. Due to the different chemical nature of the glucan species, it is often advantageous to determine the amount of cellulosic glucose separately from the starch glucan.

\section{Scope}

2.1. This Laboratory Analytical Procedure (LAP) is used to quantify the cellulose-derived glucan content in solid biomass samples that also contain varying levels of starchderived glucan.

2.2. This procedure is appropriate for solid biomass samples containing starch and structural cellulosic glucan.

2.3.All analyses should be performed in accordance with an appropriate laboratory-specific quality assurance plan (QAP).

\section{Terminology}

3.1. Glucose: A six-carbon carbohydrate common in biomass.

3.2. Glucan: A polymer of glucose units.

3.3. Cellulose: A linear chain of $\beta(1 \rightarrow 4)$ D-glucose units.

3.4. Starch: A branched polymer of $\alpha(1 \rightarrow 4)$ D-glucose units.

3.5. Cellulosic Carbohydrate Content: The total carbohydrate content that includes structural glucan, xylan, galactan, arabinan, and mannan, but specifically does not include glucan from starch. This definition conforms to the guidance in the Renewable Fuels Standards Renewable Identification Number program.

3.6. Calibration Verification Standard (CVS): An independent standard prepared from a different stock solution at a different concentration than the calibration standards. The concentration of the CVS should be set in the middle of the chosen calibration range and is used to ensure the calibration remains accurate throughout the entirety of the sample run. Additional CVS concentrations at the lower or higher end of the calibration curve can also be run to ensure accuracy of a sample's respective concentrations. 
3.7. Oven Dry Weight $(O D W)$ : The weight of biomass mathematically corrected for the amount of moisture present in the sample at the time of weighing.

3.8. Filtrate: The liquid fraction of a starch removal after filtration.

3.9. Pellet: The solid fraction of sample remaining on quartz filter after filtration subsequent starch removal.

\section{Significance and Use}

4.1. This procedure is conceptually an enzymatic removal of starch followed by an acid hydrolysis of cellulose prior to measurement of cellulosic glucans.

4.1.1. The starch removal procedure is adapted from the Megazyme published starch analysis procedure: RTS-NaOH, 2019.

4.1.2. The cellulose hydrolysis and glucose measurement are adapted from the NREL Laboratory Analytical Procedure "Determination of Structural Carbohydrates and Lignin in Biomass" NREL/TP-5100-42618.

4.2. This procedure can be used in conjunction with other procedures to determine the chemical composition of biomass samples; see LAP "Summative Mass Closure for Biomass Samples."

\section{Interferences}

5.1. Certain guard columns for carbohydrate quantification may cause artifact peaks. Individual carbohydrates should be run on new columns and guard columns to verify the absence of artifact peaks.

5.2. For the purposes of this analysis, all non-structural glucans or free glucans are considered to be of starch origin. The $\alpha$-glucan bonds of starch are much more labile than the $\beta$-glucan bonds of cellulose, and any low molecular weight glucans, such as monomeric glucose, are more likely to have derived from starch. In addition, this assumption serves to prevent misidentification of glucans as cellulosic and more valuable under the Renewable Fuels Standards Renewable Identification Number program.

5.3. The presence of protein and other soluble components may make the filtration process slow. While the use of membrane filters with larger pore size may improve the filtration rate, we have yet to investigate the precision and accuracy of a larger pore size. The use of a protease to remove the soluble proteins has not been investigated, but may improve the filtration rate without compromising the glucan quantification. 


\section{Apparatus}

6.1. Analytical balance with precision to $0.1 \mathrm{mg}$

6.2. Water bath capable of maintaining $50^{\circ} \mathrm{C} \pm 2{ }^{\circ} \mathrm{C}$ and $30^{\circ} \mathrm{C} \pm 2{ }^{\circ} \mathrm{C}$

6.3. High-performance liquid chromatograph (HPLC) system equipped with a refractive index detector and the following column:

6.3.1. Phenomenex Shodex sugar SP0810 (or equivalent) with ionic form $\mathrm{H}^{+} / \mathrm{CO}_{3}^{-}$deashing guard column

6.4. $\mathrm{pH}$ meter, accurate to $0.01 \mathrm{pH}$ unit

6.5. Vortex mixer, variable speed, capable of reaching 3,000 rpm

6.6. Magnetic stir plate, capable of stirring at $600 \mathrm{rpm}$ minimum

6.7. Vacuum oven set to $40^{\circ} \mathrm{C} \pm 2^{\circ} \mathrm{C}$

6.8. Filtration apparatus, accommodates $47-\mathrm{mm}$ diameter filter, such as VWR Cat No. 89426-768

6.9. House vacuum system or vacuum pump for filtration

6.10. Autoclave equipped with a "liquids cycle" capable of reaching and maintaining $121^{\circ} \mathrm{C}$ for 60 minutes

\section{Reagents and Materials}

\subsection{Reagents}

7.1.1. High-purity material for standards

7.1.1.1. D- $(+)-G l u c o s e, ~ \geq 99.5 \%(G C)$

7.1.1.2. An aliquot of high purity $\mathrm{D}-(+)$-Glucose, $\geq 99.5 \%(\mathrm{GC})$ from a different source (manufacturer or lot), to be used to prepare CVS

7.1.2. Sodium hydroxide pellets, ACS grade

7.1.2.1. 1.7M sodium hydroxide solution (store and use cold)

7.1.2.2. $4 \mathrm{M}$ sodium hydroxide solution for $\mathrm{pH}$ adjustment 
7.1.3. Water, HPLC grade, $0.2 \mu \mathrm{m}$ filtered (or deionized $18 \mathrm{M} \Omega / \mathrm{cm}$ filtered water)

7.1.4. Sulfuric acid, $72 \% \mathrm{w} / \mathrm{w}$ (specific gravity 1.6338 at $20^{\circ} \mathrm{C}$ )

7.1.5. Glacial acetic acid, ACS grade

7.1.5.1. 600-mM sodium acetate buffer ( $\mathrm{pH} 3.8)$

7.1.6. Thermostable $\alpha$-amylase. This procedure was developed with these specific enzymes available from Megazyme: Cat No. E-BSTAA (3,000 $\mathrm{U} / \mathrm{mL} ; 170 \mathrm{U} / \mathrm{mg}$ )

7.1.7. Amyloglucosidase. This procedure was developed with these specific enzymes available from Megazyme: Cat No. E-AMGDF-40ML (3,260 $\mathrm{U} / \mathrm{mL}$ soluble starch)

7.1.8. Calcium carbonate, ACS reagent grade

7.1.9. Calcium chloride dihydrate, ACS reagent grade

7.1.10. 190 proof ethanol, reagent grade

7.2. Materials

7.2.1. Desiccator containing desiccant

7.2.2. Highly suggested: positive displacement automatic pipettors capable of multi-dispensing, such as: Eppendorf Repeater E3x with corresponding compatible tips

OR:

Corresponding pipettors with compatible tips (ranging from $0.2 \mathrm{~mL}$ to 10 $\mathrm{mL}$ ) and a bottle topper dispensette to deliver larger volumes up to $16 \mathrm{~mL}$

7.2.3. Volumetric flasks, class A, or appropriate sizes for standard, CVS dilution and reagents

7.2.4. Pressure tubes, 120 -mL capacity, glass, with screw on PTFE caps and Oring seals (Ace glass \#8648-89, or equivalent) or glass vessels (i.e., 250$\mathrm{mL}$ Erlenmeyer flask, beaker, or serum bottle - a glass vessel matching close to or slightly larger than a $47-\mathrm{mm}$ diameter bottom), autoclave safe. Pressure vessels must be pressure rated for at least 150 psig at $120^{\circ} \mathrm{C}$ to prevent potential rupture during the autoclave step.

7.2.5. Aluminum foil, if using unsealed acid hydrolysis vessels 
7.2.6. Teflon or glass stir rods, in appropriate size for dilute acid hydrolysis vessel

7.2.7. Magnetic stir bars, $10 \times 6.4 \mathrm{~mm}$, such as VWR Cat No: $89030-550$

7.2.8. Nylon or polypropylene sample racks to accommodate tubes with outer diameters (OD) of $30 \mathrm{~mm}$ and $16 \mathrm{~mm}$

7.2.9. Metal sample racks to accommodate tubes with OD $38.1 \mathrm{~mm}$ (if using pressure tubes for acid hydrolysis)

7.2.10. $50-\mathrm{mL}$ conical polypropylene centrifuge tube with a tightly fitting screw cap

7.2.11. Quartz fiber filters, $47 \mathrm{~mm}$, efficiency rating: $>99 \%$ retention DOP at 3 $\mu \mathrm{m}$, such as: Advantec QR-100

7.2.12. Autosampler vials, crimp-top, $2-\mathrm{mL}$ fill volume

7.2.13. $\mathrm{pH}$ paper (range 2-9)

7.2.14. Aluminum sample pans, $70 \mathrm{~mL}$

7.2.15. Disposable syringes, $3 \mathrm{~mL}$, fitted with $0.2-\mu \mathrm{m}$ nylon syringe filters

7.2.16. Disposable culture tubes, $16 \times 100 \mathrm{~mm}$ (if using pressure tubes for acid hydrolysis)

\section{Environmental Safety and Health Considerations and Hazards}

8.1. Sodium hydroxide is corrosive and should be handled with care.

8.2. Sulfuric acid is corrosive and should be handled with care.

8.3. Glacial acetic acid is corrosive and flammable. It should be handled with care, utilizing proper ventilation when in use.

8.4. Follow all applicable chemical handling procedures, such as those provided by safety data sheets.

8.5. Pressure vessels must be pressure rated for at least 150 psig at $120^{\circ} \mathrm{C}$ to prevent potential rupture during the autoclave step.

8.6. Cut-resistant gloves should be used while removing Teflon caps from pressure vessels because glassware can shatter due to thermal cycling. 


\section{Sampling, Test Specimens, and Test Units}

9.1. Prior to analysis, test material should be dried according to ASTM E1757-19, Preparation of Biomass for Compositional Analysis, which stipulates that starchcontaining materials should not be dried at temperatures above $65^{\circ} \mathrm{C}$ to prevent formation of retrograde starches, which are resistant to analysis.

9.1.1. Samples may be dried at $50^{\circ} \mathrm{C} \pm 3^{\circ} \mathrm{C}$ for up to 48 hours or in a freeze drier until moisture content is measured at less than $8 \%$.

9.2. Care must be taken to ensure a representative sample is used for analysis. The sample for analysis should be at room temperature.

\section{Procedure}

10.1. Prepare solutions and reagents as follows:

10.1.1. Prepare a sodium hydroxide solution (4M) for $\mathrm{pH}$ adjustment by adding $80 \mathrm{~g}$ of sodium hydroxide pellets to $400 \mathrm{~mL}$ of filtered deionized water in a $500-\mathrm{mL}$ volumetric flask. Dissolve by stirring, taking care as this solution will get hot. Adjust to a final volume of $500 \mathrm{~mL}$.

10.1.2. Prepare a sodium acetate buffer $(600 \mathrm{mM}, \mathrm{pH} 3.8)$ by adding $69.6 \mathrm{~mL}$ of glacial acetic acid $(1.06 \mathrm{~g} / \mathrm{mL})$ to $1600 \mathrm{~mL}$ of deionized filtered water and adjust to $\mathrm{pH} 3.8$ using a $4 \mathrm{M}$ sodium hydroxide solution. Add $1.48 \mathrm{~g}$ of calcium chloride dihydrate and dissolve by stirring. Quantitatively transfer volume to a 2-L volumetric flask and adjust the final volume to 2 $\mathrm{L}$ with deionized filtered water.

10.1.3. Prepare a sodium hydroxide solution (1.7M) for resistant starch removal by adding $68 \mathrm{~g}$ of sodium hydroxide pellets to $900 \mathrm{~mL}$ of deionized filtered water in a 1-L volumetric flask. Dissolve by stirring, taking care as this solution will get hot. Adjust to a final volume of $1 \mathrm{~L}$, allow to cool to room temp. Store in the refrigerator.

\subsection{Starch Removal (adapted from Megazyme published procedure: RTS-NaOH, 2019)}

10.2.1. Add $200 \mathrm{mg} \pm 10 \mathrm{mg}$ of sample to a tared 50-mL conical polypropylene centrifuge tube with a tightly fitting screw cap. Record the weight to the nearest $0.1 \mathrm{mg}$. LAP "Determination of Total Solids in Biomass" should be performed at the same time, to accurately measure the percent solids for correction. Each sample should be analyzed in triplicate at minimum.

10.2.2. Add $0.4 \mathrm{~mL}$ of 190 proof ethanol and vortex vigorously. This will aid in sample dispersion. 
10.2.3. Add $4 \mathrm{~mL}$ cold $1.7 \mathrm{M} \mathrm{NaOH}$ solution and vortex for 15 seconds.

10.2.4. Add a stir bar to the sample tube and place the tube over a magnetic stir plate for 15 minutes. Ensure that the liquid is moving inside the tubes. Vortex samples intermittently 2 to 3 times over the 15 minutes, ensuring there are no lumps present in slurry.

10.2.5. Add $16 \mathrm{~mL}$ of $600 \mathrm{mM}$ sodium acetate buffer, vortexing sample during buffer addition to ensure the mixture is homogenous.

10.2.6. Check that the sample $\mathrm{pH}$ is approximately 5 with $\mathrm{pH}$ paper.

10.2.7. Immediately add $0.2 \mathrm{~mL}$ of $\alpha$-amylase followed by $0.2 \mathrm{~mL}$ of amyloglucosidase to the sample tube. Re-cap tube and vortex for 3 seconds.

10.2.8. Place sample tube into the $50^{\circ} \mathrm{C} \pm 2^{\circ} \mathrm{C}$ water bath, ensuring the water level is above the level of sample volume in tube.

10.2.9. Incubate samples for 60 minutes. Vortex samples half-way through incubation to ensure enzyme dispersion.

10.2.10. Remove from bath. Vortex samples, and invert tubes to ensure condensed water on the inside of the lid is mixed with the liquid in the tube.

10.2.11. Allow samples to come to room temperature.

10.2.12. Vacuum filter each sample through a quartz fiber filter. Collect an aliquot of undiluted filtrate for further analysis by HPLC if desired.

10.2.13. Rinse all particulates from tube and the sides of the filtration apparatus with filtered deionized water, ensure a complete transfer of material to filter.

10.2.14. Place pellet and quartz filter onto an aluminum pan and place in a $40^{\circ} \mathrm{C}$ $\pm 2^{\circ} \mathrm{C}$ vacuum oven to dry, preferably overnight.

\subsection{Acid Hydrolysis of Cellulosic Pellet}

10.3.1. Determine the appropriate ratio of hydrolysis volumes needed. According to LAP "Determination of Structural Carbohydrates and Lignin in Biomass," utilizing a 300-mg starting sample, $3 \mathrm{~mL}$ of $72 \%$ sulfuric acid and $84 \mathrm{~mL}$ of filtered deionized water are used. An estimated low cellulose containing material should be performed at $1 / 3$ the scale $(1 \mathrm{~mL}$ of $72 \%$ sulfuric acid and $28 \mathrm{~mL}$ of filtered deionized 
water) for acid hydrolysis. A high-cellulose-containing material should be performed at $2 / 3$ the full volumes $(2 \mathrm{~mL}$ of $72 \%$ sulfuric acid and 56 $\mathrm{mL}$ of filtered deionized water).

10.3.2. Place a de-starched, dried sample pellet with corresponding filter into a disposable culture tube by carefully folding the filter ensuring all particulates are transferred into the tube.

10.3.2.1. If using a hydrolysis vessel other than a pressure tube, insert the sample directly into the hydrolysis vessel of choice.

10.3.3. Add the previously determined volume of $72 \%$ sulfuric acid to the pellet ( 1 or $2 \mathrm{~mL})$, enabling as much saturation as possible.

10.3.4. Knead the pellet and filter with a Teflon stir rod to ensure proper acid contact. Address any dry spots, ensuring complete saturation of sample with acid.

10.3.5. Suspend all vessels in a water bath at $30^{\circ} \mathrm{C} \pm 2^{\circ} \mathrm{C}$ for 1 hour.

10.3.6. Knead the sample continuously throughout the incubation, approximately every 5 minutes.

10.3.7. Remove the vessels from the water bath and adjust the concentration of sulfuric acid to $4 \%$ by adding the appropriate volume of filtered deionized water $(28$ or $56 \mathrm{~mL})$.

10.3.7.1. Using the appropriate final volume of water, quantitatively transfer contents of culture tube to a pressure tube, ensuring all material is transferred completely. This is best performed by using several small aliquots of water to rinse the culture tube and stir rod, ensuring only the final total volume of water is added to the pressure tube.

10.3.7.2. If using a hydrolysis vessel other than a pressure tube, dilute the sample with the pre-determined final volume, ensuring all material is rinsed into the hydrolysis vessel.

NOTE: Use of sealed pressure vessels for dilute acid hydrolysis is preferred as it prevents evaporation during the autoclave step. If a sealed vessel is not used, water lost to evaporation must be accounted for by weighing the vessel and contents before and after the autoclave step. Deionized filtered water must be added to each vessel equal to the weight of mass lost during autoclaving prior to HPLC analysis. 
10.3.8. Cap the hydrolysis vessel. Vessels without a cap can be covered with aluminum foil to minimize the evaporative loss of water.

10.3.9. Invert capped hydrolysis vessels to ensure homogeneity, taking care to get the sample particulates in solution. Vessels without a cap should be swirled thoroughly to achieve the same purpose.

10.3.10. Autoclave samples and sugar recovery standards (SRS) (see steps 10.3.11 through 13 ) for 1 hour at $121^{\circ} \mathrm{C}$ on liquids cycle.

10.3.11. Allow samples to slowly cool until they are safe to handle.

10.3.12. Prepare a set of SRS that will be taken through the autoclave procedure and used to correct for loses due to decomposition of sugars during dilute acid hydrolysis.

10.3.12.1. Refer to Table 1 for SRS concentration suggestions. SRS concentrations should be chosen to most closely resemble the concentrations of sugars in the sample. A fresh SRS is not required for every analysis. It is recommended that a large batch be produced to be utilized over a period of time.

10.3.12.2. Weigh out the desired concentration of each sugar to the nearest $0.1 \mathrm{mg}$.

10.3.12.3. Add appropriate final volume of filtered deionized water.

10.3.12.4. Dispense in $10.0-\mathrm{mL}$ aliquots into sealed containers, and label.

10.3.12.5. They may be stored in a freezer and removed when needed.

10.3.12.6. Thaw and vortex the frozen SRS prior to use. If frozen SRS are used, the appropriate amount of acid must be added to the thawed sample and vortexed prior to transferring to a hydrolysis vessel.

Table 1: Suggested concentrations for sugar recovery standards

\begin{tabular}{|l|l|}
\hline Component & $\begin{array}{l}\text { Sugar } \\
\text { concentrations } \\
(\mathrm{mg} / \mathrm{mL})\end{array}$ \\
\hline Glucose & 5 \\
\hline
\end{tabular}

10.3.13. Add the appropriate amount of $72 \%$ sulfuric acid to each SRS. SRS samples should be run in triplicate.

10.3.13.1. For a starting $\mathrm{pH}$ of 7 and $10-\mathrm{mL}$ volume, the amount of $72 \%$ sulfuric acid needed will be $348 \mu \mathrm{L}$. 
10.3.14. Split the SRS in half, placing $5 \mathrm{~mL}$ into a hydrolysis vessel and autoclave with the batch for 1 hour at $121^{\circ} \mathrm{C}$ on liquids cycle.

10.3.15. Take the remaining $5 \mathrm{~mL}$ of SRS and neutralize it for analysis on the HPLC (see 10.4.2) to obtain starting SRS concentration.

\subsection{Analyze Samples for Monomeric Sugars}

10.4.1. Prepare standards and control samples for analysis.

10.4.1.1. Prepare a series of standards containing glucose, referring to Table 2 for suggested concentration range. Use a five-point calibration. If standards are prepared outside of the suggested ranges, the new range for these calibration curves will need to be validated. The suggested standards are also available to purchase as a custom mix from various vendors. Method development was performed using Absolute Standards custom mix.

Table 2. Suggested Concentration Ranges for 10.3.1 Calibration Standards

\begin{tabular}{|l|l|}
\hline Component & $\begin{array}{l}\text { Suggested } \\
\text { concentration range } \\
\text { (mg/mL) }\end{array}$ \\
\hline $\mathrm{D}(+)$ glucose & $0.01-6.0$ \\
\hline CVS & $\begin{array}{l}\text { Middle of linear range, } \\
\text { concentration not equal } \\
\text { to a calibration point. }\end{array}$ \\
\hline
\end{tabular}

10.4.1.2. A fresh set of standards is not required for every analysis. A large batch of standards may be produced, filtered through $0.2-\mu \mathrm{m}$ filters into autosampler vials, sealed, and labeled. The standards and CVS samples may be stored in a freezer and removed when needed. Thaw and vortex frozen standards prior to use. During every use, standards and CVS samples should be observed for unusual concentration behavior. Unusual concentrations may mean that the samples are compromised or volatile components have been lost. Assuming enough volume was initially dispensed, standards and CVS samples should not have more than 12 injections drawn from a single vial. In a chilled autosampler chamber, the lifetime of carbohydrate standards and CVS samples is approximately three to four days. 
10.4.1.3. Prepare an independent CVS for each set of calibration standards. Use reagents from a source or lot other than that used in preparing the calibration standards. Prepare the CVS at a concentration that falls in the middle of the validated range of the calibration curve. The CVS should be analyzed on the HPLC after each calibration set and at regular intervals throughout the sequence, bracketing groups of samples. The CVS is used to verify the quality and stability of the calibration curve(s) throughout the run.

\subsubsection{Prepare Samples for HPLC analysis}

10.4.2.1. Vortex or swirl each sample vessel to ensure homogeneity. Decant an aliquot of sample ( $10 \mathrm{~mL}$ is recommended) into a conical centrifuge tube. Using calcium carbonate, neutralize each sample to a pH between 6 and 7 .

10.4.2.2. Prepare the sample for HPLC analysis by passing the neutralized liquid through a $0.2-\mu \mathrm{m}$ nylon syringe filter into an autosampler vial. Seal and label the vial. Prepare each sample in duplicate if desired. If it is suspected that the sample concentrations may exceed the calibration range, dilute the samples as needed, recording the dilution. The concentrations should be corrected for dilution after running. If necessary, neutralized samples may be stored in the refrigerator for three or four days. After this time, the samples should be considered compromised.

10.4.3. Analyze the calibration standards, CVS, and samples by HPLC using a Shodex sugar SP0810, $300 \times 8 \mathrm{~mm}$, column equipped with the appropriate guard column.

10.4.4. See Appendix 1 for HPLC operating conditions for sample analysis. 


\section{Calculations}

11.1. Create a calibration curve for glucose to be quantified using linear regression. From this curve, determine the concentration in $\mathrm{mg} / \mathrm{mL}$ of the component present in the samples analyzed by HPLC, correcting for dilution if required.

11.2. Calculate and record the amount of each CVS recovered following HPLC analysis.

$$
\% \text { CVS recovery }=\frac{\text { conc. detected by } H P L C, m g / m L}{\text { known conc. of standard, } m g / m L} \times 100
$$

11.3. For the SRS, calculate the amount of glucose recovered after dilute acid hydrolysis, accounting for any dilution made prior to HPLC analysis. Average any replicate $\left(\% \mathrm{R}_{\text {sugar }}\right)$ values obtained for glucose and report $\% \mathrm{R}_{\text {avg, sugar. }}$

$$
\% R_{\text {sugar }}=\frac{C_{\text {post }}}{C_{\text {pre }}} \times 100
$$

where:

$$
\begin{aligned}
& \mathrm{C}_{\text {post }}=\text { post hydrolysis concentration of glucose as determined by HPLC, } \\
& \mathrm{C}_{\text {pre }}=\text { pre-hydrolysis concentration of glucose as determined by HPLC, }
\end{aligned}
$$

11.4. Use the percent hydrolyzed sugar recovery values calculated in step 11.3 to correct the corresponding sugar concentration values obtained by HPLC for each of the hydrolyzed samples $\left(\mathrm{C}_{\mathrm{cor} \text { s sample }}\right)$, accounting for any dilution made prior to HPLC analysis, including the addition of sulfuric acid to adjust $\mathrm{pH}$

$$
C_{x}=\frac{C_{H P L C} \times \text { dilution factor }}{\% R_{\text {avg.sugar }} \div 100}
$$

where:

$$
\begin{aligned}
& \mathrm{C}_{\mathrm{HPLC}}=\text { concentration of glucose as determined by HPLC, } \mathrm{mg} / \mathrm{mL} \\
& \% \mathrm{R}_{\text {avg. sugar }}=\text { average recovery SRS glucose } \\
& \mathrm{C}_{\mathrm{x}}=\mathrm{C}_{\text {cor. sample, concentration in } \mathrm{mg} / \mathrm{mL} \text { of glucose in the hydrolyzed }} \text { sample after correction for loss on } 4 \% \text { hydrolysis. }
\end{aligned}
$$


11.5. To calculate the concentration of glucan in the original sample:

where:

$$
\% \operatorname{Carb}=\frac{C_{x} \times V \times A}{M_{x}}
$$

$\mathrm{C}_{\mathrm{x}}=$ concentration in $\mathrm{mg} / \mathrm{mL}$ of glucose in the hydrolyzed sample after correction for loss on $4 \%$ hydrolysis

$\mathrm{V}=$ Volume of hydrolysis $(28.9 \mathrm{~mL}$ or $57.82 \mathrm{~mL}$ depending on starting material, adjusted for density changes)

$\mathrm{A}=$ Correction for the weight of water added during hydrolysis. 162/180 for glucose to glucan conversion.

$$
\mathrm{M}_{\mathrm{x}}=\mathrm{ODW} \text { of starting sample material }
$$

11.6. To report or calculate the relative percent difference (RPD) between two samples, use the following calculation:

$$
R P D=\left(\frac{\left(X_{1}-X_{2}\right)}{X_{\text {mean }}}\right) \times 100
$$

where:

$$
\begin{aligned}
& X_{1} \text { and } X_{2}=\text { measured values } \\
& X_{\text {mean }}=\text { the mean of } X_{1} \text { and } X_{2}
\end{aligned}
$$

11.7. To report or calculate the root mean square (RMS) deviation or the standard deviation (stdev) of the samples, use the following calculations.

First find the RMS of the sample using:

$$
R M S=x_{m}=\text { mean }=\sqrt{\left(\frac{\sum_{1}^{n} x}{n}\right)^{2}}
$$

Then find the root mean square deviation, or stdev, using:

$$
R M \text { Sdeviation }=\sigma=\operatorname{stdev}=\sqrt{\frac{\sum_{1}^{n}\left(X_{i}-X_{m}\right)^{2}}{n}}
$$

where:

$$
\begin{aligned}
& \mathrm{x}_{m}=\text { the root mean square of all } \mathrm{x} \text { values in the set } \\
& \mathrm{n}=\text { number of samples in set } \\
& \mathrm{x}_{i}=\text { a measured value from the set }
\end{aligned}
$$




\section{Report Format}

12.1. Report concentrations of target components in percent of ODW. RPD and RMS deviation may also be reported.

\section{Precision and Bias}

13.1. Precision and bias need to be determined by data quality objectives and laboratory specific QAP.

\section{Quality Control}

14.1. Reported Significant Figures: Figures need to be determined by data quality objectives and laboratory-specific QAP.

14.2. Replicates: It is recommended that the samples be run in triplicate to verify reproducibility on differing analytical instruments.

14.3. Blank: a solution and media blank can be used to ensure no co-eluting peaks and that there are no detectable compounds present in the media or reagents due to contamination upon preparation. Concurrently an instrument blank may be run, using filtered deionized water analyzed by HPLC in the same manner as samples.

14.4. Control Sample: Include a commercially available known control sample with every batch to assess method performance. If unavailable, at minimum use a chemical grade corn starch to evaluate starch removal process. Analyze, in triplicate, sugar recovery standards to account for loss during autoclaving.

14.5. Relative Percent Difference Criteria: Criteria need to be determined by data quality objectives and laboratory-specific QAP.

14.6. Calibration Verification Standard: CVS should be independently prepared and analyzed as described in the procedure section.

14.7. Sample Storage: Store samples in sealed containers so the volatile component concentration remains constant. Samples should be stored in a refrigerator. If necessary, neutralized samples may be stored in a refrigerator for 3 to 4 days. After this time the samples should be considered compromised. Neutralized samples may need to be re-filtered after storage in a refrigerator if precipitate is visible.

14.8. Standard Preparation: Standards should be prepared as described in the procedure. 
14.9. Standard Storage: The standards should be stored in a freezer and removed when needed. Thaw and vortex standards prior to use.

14.10. Definition of a Batch: A batch is any number of samples that are analyzed and recorded together. The maximum size of a batch will be limited by the equipment constraints.

\section{Appendices}

15.1. See Appendix 1 at the end of the document for the HPLC operating conditions.

\section{Bibliography}

All NREL Biomass Compositional Anlaysis Laboratory Procedures referenced in this document can be found here: https://www.nrel.gov/bioenergy/biomass-compositional-analysis.html.

McCleary, B.V., L. M. J. Charmier, and V. A. McKie, Megazyme, "Measurement of Starch: Critical Evaluation of Current Methodology," Starch 1800146, no. 71 (2018): 1-13, DOI: 10.1002/star.201800146.

The Megazyme starch assay procedure referenced in this document can be found at https://www.megazyme.com/documents/Booklet/K-TSTA-100A_DATA.pdf.

Sluiter, J.B., K.P. Michel, B. Addison, Y. Zeng, W. Michener, A.L. Paterson, F.A. Perras, and E.J. Wolfrum. "Direct Determination of Cellulosic Glucan Content in Starch-Containing Samples," Cellulose (2021). https://doi.org/10.1007/s10570-020-03652-2.

Zhou, J., and L. Zhang. "Solubility of Cellulose in NaOH/Urea Aqueous Solution," Polym $J 32,866-870$ (2000). https://doi.org/10.1295/polymj.32.866. 


\section{Appendix 1}

\section{HPLC operating conditions for sample analysis:}

Injection volume: $50 \mu \mathrm{L}$, dependent on concentration and detector limits

Mobile phase: HPLC grade water, $0.2 \mu \mathrm{m}$ filtered and degassed

Flow rate: $0.6 \mathrm{~mL} /$ minute

Autosampler temperature: $4^{\circ} \mathrm{C}$

Column temperature: $80^{\circ} \mathrm{C}-85^{\circ} \mathrm{C}$

Detector temperature: as close to column temperature as possible

Detector: refractive index

Run time: 20-minute data collection plus 15-minute post run (with possible adjustment for later eluting compounds)

NOTE: The deashing guard column should be placed outside of the heating unit and kept at ambient temperature. This will prevent artifact peaks in the chromatogram.

See section 11 for calculations.

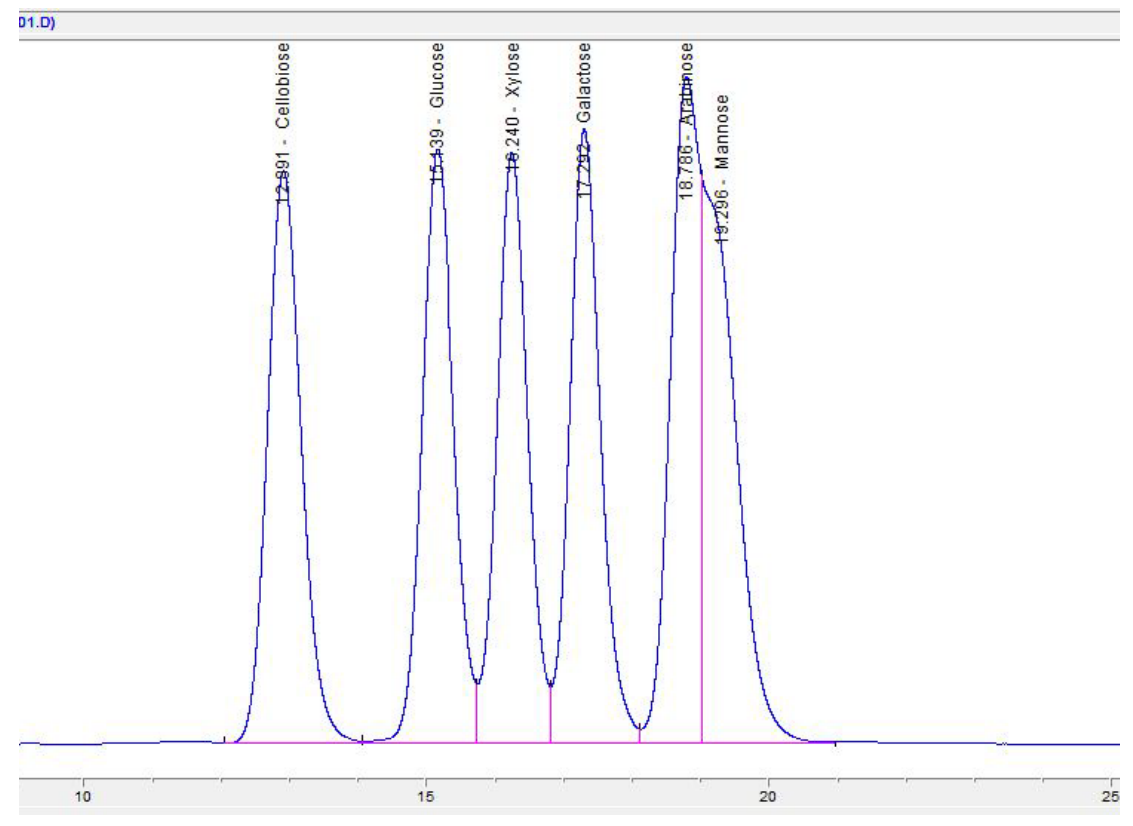

Fig 1. Sample chromatogram, elution pattern of carbohydrates with common biomass carbohydrates 